\title{
Hybrid Fuzzy-Sliding Control Scheme for Bi-directional SEPIC Converter in Renewable Based DC Microgrid
}

\author{
Fredy H. Martínez S. ${ }^{\# 1}$, Fernando Martínez S. ${ }^{\# 2}$ and Edwar Jacinto G. ${ }^{\# 3}$

 \\ Carrera 13 \#40-53, Bogotá D.C., Colombia \\ ${ }^{1}$ fhmartinezs@udistrital.edu.co \\ ${ }^{2}$ fmartinezs@udistrital.edu.co \\ 3 ejacintog@udistrital.edu.co
}

\begin{abstract}
This paper describes a hybrid fuzzy-sliding control scheme for bi-directional SEPIC converter in renewable based DC microgrids. The performance of a DC microgrid is directly dependent on the voltage stability of the DC bus. In operation, the voltage level of the system is affected by the power injection of the power sources connected to the microgrid, in particular those dependent on environmental factors (such as sun and wind), and by the power consumption of non-constant loads. This feature of microgrids makes control a complex engineering problem. Considering this problem, we propose a hybrid control scheme for a SEPIC bi-directional converter capable of regulating the power flow and stabilizing the system's DC bus. Proposed control technique is simulated in a 48 V DC microgrid and results are provided.
\end{abstract}

Keyword - Bi-directional converter, Fuzzy-sliding control, Microgrid, SEPIC converter

\section{INTRODUCTION}

Colombia has large regions without electricity service (the coverage of electricity service is only $34 \%$ ), are regions isolated from the traditional power grid (about $52 \%$ of the national territory, and inhabited by about $1,800,000$ people) which have been called Non-Interconnected Zones (ZNI) [1]. There are many reasons for this type of deprivation of electricity service, but the most common reason is the high cost of installing the network to power an area with low population density. The most promising solution for supplying electricity to these areas is the installation of microgrids. The global market trend indicates that microgrids are becoming consolidated as an energy solution for the end user (and not necessarily for those not connected to the traditional power grid) that can even bring economic benefits [2].

A microgrid is a localized group of different kinds of electrical energy sources, which work together to meet the energy needs of a specific area, and which can operate either in conjunction with the traditional power grid or in isolation [3]. This microgrid integrates different energy sources according to the energy availability of the area (solar energy, wind turbines, coal, liquefied petroleum gas, etc., although with a strong propensity for renewable resources, or renewable distributed energy resources - DER), and have a variable architecture according to the advantage of generating energy primarily from one or another energy source. This variable topology makes microgrid control and protection complex and an open-ended engineering research problem [4, 5], particularly when considering power flow problems, load sharing, voltage regulation and mitigation of various kinds of power quality issues [6].

A great energetic advantage of the microgrids is their greater electrical efficiency when feeding electronic type loads as variable speed drives and LED loads, because they do not need AC/DC and DC/AC converters when feeding them directly in direct current (DC) [7, 8]. The DC power supply system has other advantages over the AC (alternating current) system, for example, it has higher reliability and lower cost (disappear problems of reactive power control, skin effect and frequency synchronisation).

Among the main issues in the design and control of a DC microgrid are the selection of power converter topologies, voltage control and load sharing $[9,10]$. This paper focuses on the problem of controlling the bidirectional DC/DC converter connected to the power storage system (batteries) by considering the DC bus voltage. It should be remembered that in a microgrid renewable energy sources (such as solar and wind) have fluctuating power characteristics due to environmental factors, and that in general a microgrid also operates with variable loads.

The voltage level in a DC system is a fundamental design parameter since it directly affects the performance of the microgrid. As stated in [7], an excellent DC voltage option for residential applications is a $48 \mathrm{~V}$ system. This voltage level is chosen considering losses in both the medium power distribution grid and the electronic power converters required in the installation. In addition, $48 \mathrm{~V}$ is considered a safe voltage level for humans. 
The performance of a DC microgrid is determined by the voltage regulation on the system's DC bus [11]. The DC voltage regulation of the inverter must guarantee a constant voltage regardless of the conditions of the generating sources and the load $[12,13]$. The voltage varies in relation to the amount of power injected into the DC bus by the power sources, and by the continuous changes in the load due to power requirements. Power converters require a good monitoring and control scheme for this voltage.

This paper proposes the use of a bi-directional SEPIC (Single-Ended Primary-Inductor) converter with a hybrid fuzzy-sliding control scheme to keep the system's DC bus voltage within a range, using a battery as a power source and sinking unit $[14,15]$. The DC bus voltage is designed at $48 \mathrm{~V}$, while the battery has a $24 \mathrm{~V}$ voltage. The control strategy establishes two control surfaces according to the energy in the converter, and establishes specific operating rules for each of them.

The following part of the paper is arranged in this way. Section 2 presents preliminary concepts and problem formulation. Section 3 illustrates the design profile and development methodology. Section 4 we present the preliminary results. And finally, in Section 5, we present our conclusions.

\section{Problem Formulation}

The microgrids have proven to be an excellent alternative for the supply of electrical energy to users in remote areas without access to the electrical power grid. The topology of these microgrids integrate different energy sources, different types of loads and the possibility of connection to the power grid. These characteristics make their design and control complex.

In the case of DC microgrids, a system with better electrical performance and efficiency can be obtained by feeding electronic loads directly into DC. For these systems, DC bus voltage regulation is fundamental to system performance. The DC bus voltage is affected by the injection of electrical power from electrical power sources, and the extraction of electrical power from the load, which is generally not constant. The DC microgrid topology considered in this research is shown in Fig. 1. Loads, power sources, storage elements and the AC grid are connected to the DC voltage bus through electronic power converters.

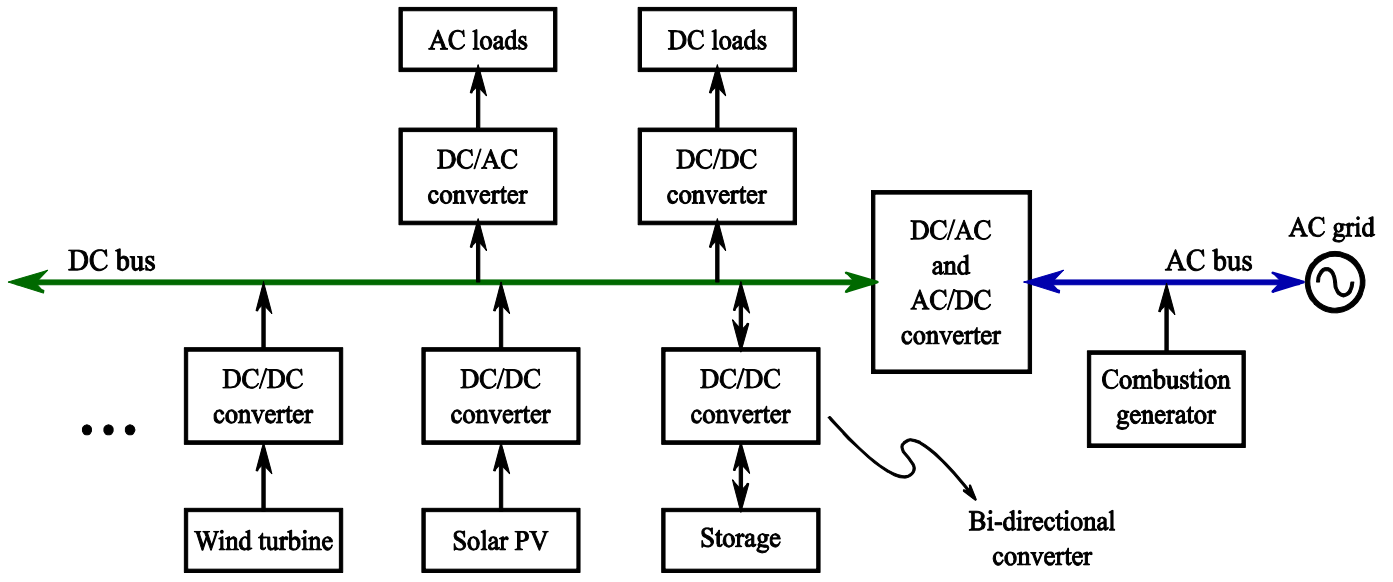

Fig. 1. Block diagram of considered DC microgrid topology

DC bus monitoring and control can be performed with a bi-directional DC/DC converter. The control of this converter must regulate the $\mathrm{DC}$ bus voltage by extracting and returning power to the storage unit according to the system requirements. Because the load and generation behaviour is unpredictable, converter control becomes complex. The use of the DC/DC converter has other advantages, such as the possibility to supply electronic loads directly on DC, leaving aside the active power factor correctors. However, these converters have a nonlinear dynamics, which makes their design more difficult.

The control system of the bi-directional SEPIC converter must be able to maintain the DC bus voltage within a tolerance range. To do this, power must be taken/injected from the storage unit (battery) to the DC bus. The SEPIC is a DC/DC converter with a single switch/control, capable of regulating DC voltages of any value. This power topology can be modified by means of an auxiliary circuit that allows the power flow to the batteryand making it bi-directional (Fig. 2). In the circuit of Fig. 2 we have included the parasitic resistors of the DC chokes and the capacitors of the converter. In addition, the fast recovery diode has been replaced by a transistor to explicitly control its conduction time, as there are now three switches that must operate during the same $T$ switching period. 


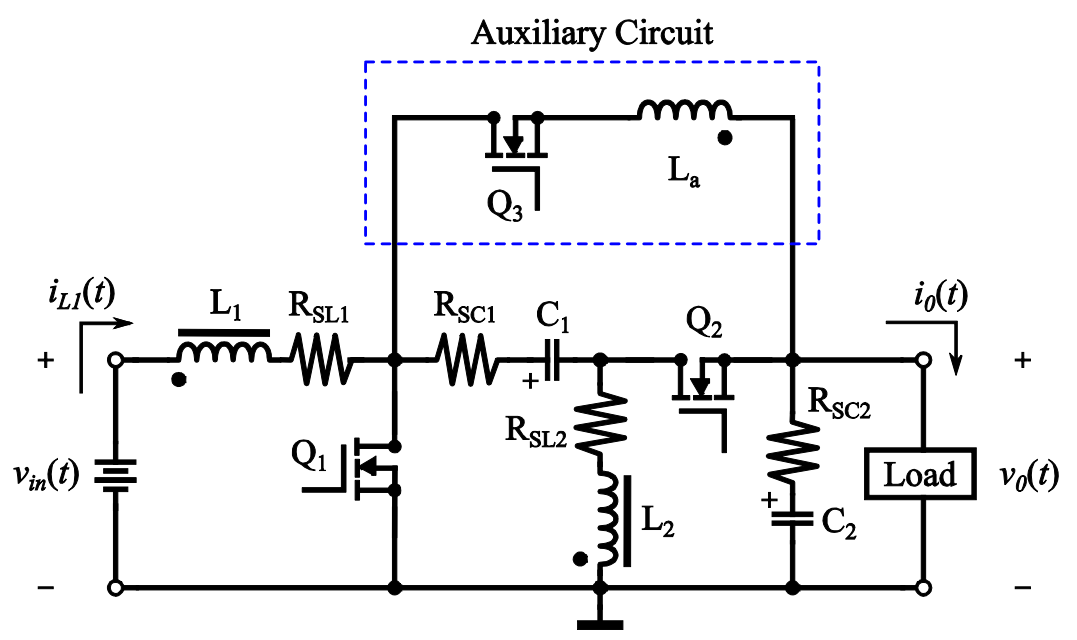

Fig. 2. Bi-directional SEPIC DC/DC converter

By controlling the duty cycle of the three semiconductor switches it is possible to increase or decrease the voltage on the DC bus of the microgrid. The transistors are working as a switch with on/off times dynamically determined according to the input energy in the converter. This energy is estimated from the input current or current in the $\mathrm{L}_{1} \mathrm{DC}$ choke. The control scheme defines two control surfaces according to how far the input current is from the expected value: near the set point and far from the set point. This current loop also guarantees stable operation of the converter. The DC bus voltage is $48 \mathrm{~V}$, and the storage battery has a nominal voltage of $24 \mathrm{~V}$, besides, any number of sources or the loads can be present.

\section{MeTHODOLOGY}

The proposed scheme for DC bus regulation proposes the use of a bi-directional DC/DC converter and a DC power storage system (battery). The purpose of the control unit is to regulate the voltage and power in the DC bus, which requires controlling the power flow to and from the battery. The selected power converter is the SEPIC, but with an auxiliary circuit to allow the flow of power from output to input (Fig. 2).

The main circuit uses two switches as in the unidirectional SEPIC, but in this case both are directly controlled with control signals at their gate (two transistors, $\mathrm{Q}_{1}$ and $\mathrm{Q}_{2}$ ). The rest of the circuit is identical to the unidirectional SEPIC: two DC chokes and capacitive filters. The auxiliary circuit achieves the power flow in the opposite direction, and uses another switch (an additional transistor, $\mathrm{Q}_{3}$ ) and another $\mathrm{DC}$ choke $\left(\mathrm{L}_{\mathrm{a}}\right)$.

The switching of $\mathrm{Q}_{1}$ and $\mathrm{Q}_{2}$ controls the voltage regulation on the DC bus, sending power to the load. $\mathrm{Q}_{3}$ switching allows power to be sent to the battery. According to these requirements the duty cycles of the three transistors $\left(\mathrm{d}_{1}, \mathrm{~d}_{2}\right.$ and $\left.\mathrm{d}_{3}\right)$ are calculated (Fig. 3).

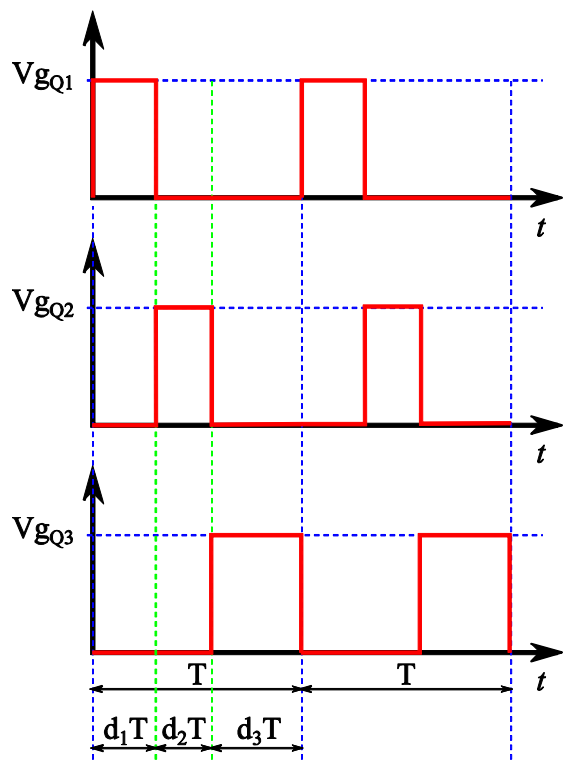

Fig. 3.Drive control signals per switching period 
This bi-directional converter has three modes of operation during a T-switching period:

- Mode $1\left(t_{0}-t_{1}\right)$ : This mode is similar to the $t_{O N}$ of a unidirectional SEPIC. The flow of currents is shown in Fig. 4(a).

- Mode $2\left(t_{1}-t_{2}\right)$ : This mode is similar to the $t_{O F F}$ of a unidirectional SEPIC. The flow of currents is shown in Fig. 4(b).

- Mode $3\left(t_{2}-t_{3}\right)$ : In this mode only the auxiliary circuit switch is closed, allowing power flow to the battery. The flow of currents is shown in Fig. 4(c).



(a)
Mode $1\left(t_{0}-t_{1}\right)$

Mode $2\left(t_{1}-t_{2}\right)$

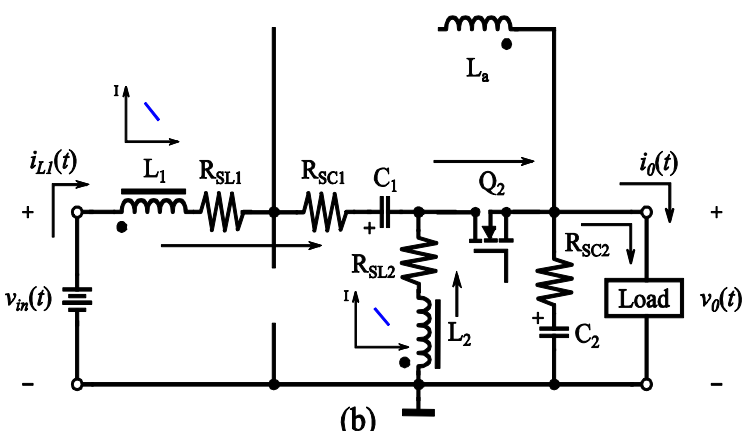

(b)

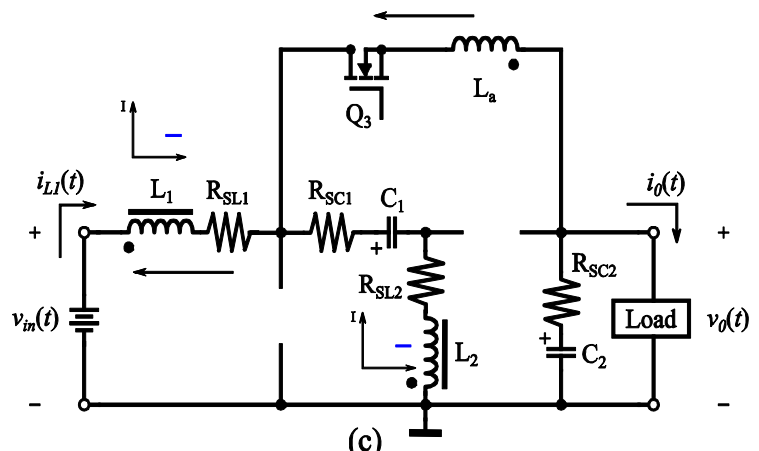

Mode $3\left(t_{2}-t_{3}\right)$

Fig. 4. The three operating modes of the bi-directional SEPIC converter

For the design of the control strategy we use the average motion of the current at the input choke $\mathrm{L}_{1}$ (to estimate the system power) and the output voltage (regulation requirement) as state variables. Since the control objective is output voltage regulation, the sliding surface in state variables for steady-state control (near the set point) is given by (Ecu. 1):

$$
S=\left\{\mathbf{X}(t) \in \mathbb{R}^{2}: \quad \overline{v_{0}(t)}=V_{\text {ref }}\right\}
$$

Where:

- $\overline{v_{0}(t)}$ is the average output voltage.

- $V_{\text {ref }}$ is the desired output voltage.

However, the surface of the Ecu. 1 does not guarantee the stability of the converter. In order to guarantee the stability of the converter, it is necessary to regulate the input energy, which can be done by assuming the input current (current in the $\mathrm{L}_{1}$ choke) as the control surface, which is equal to a constant depending on the output power (Ecu. 2).

$$
S=\left\{X(t) \in \mathbb{R}^{2}: \quad \overline{l_{L 1}(t)}=K\right\}
$$


However, the primary objective of the converter remains the regulation of the output voltage, which is why it is necessary to eliminate the stationary error of the converter. This being the case, one might think of the need for two different control surfaces to solve the problem, one operating near the steady state equilibrium point, and the other operating during converter transients. The unification of these two control strategies into a single one is done by means of a fuzzy control block, hence the name given to the control strategy used. A fuzzy control scheme allows us to build a different control surface for each rule of the system, allowing us to use the most appropriate control surface at any given time.

Then, the proposed control scheme has two feedback loops: a current loop and a voltage loop. The dynamics of the current loop is much faster than that of the voltage loop, because a fast dynamic response is required depending on the energy handled by the converter, similar to the way the control is performed in current mode. The voltage loop, which is slower dynamic in order to avoid oscillations in the output voltage due to noise in the feedback signal, is in charge of establishing the current reference for the internal loop (current loop).

The reference value of the current in the choke is automatically adjusted by the converter according to the power balance condition. For the implementation, the following variables are selected as antecedents: (1) the output voltage error, $E_{u}$, and (2) the current in the converter choke $i_{L 1}$.

For the fuzzy section, a total of seven fuzzy sets are defined for the output voltage error as shown in Fig. 5.

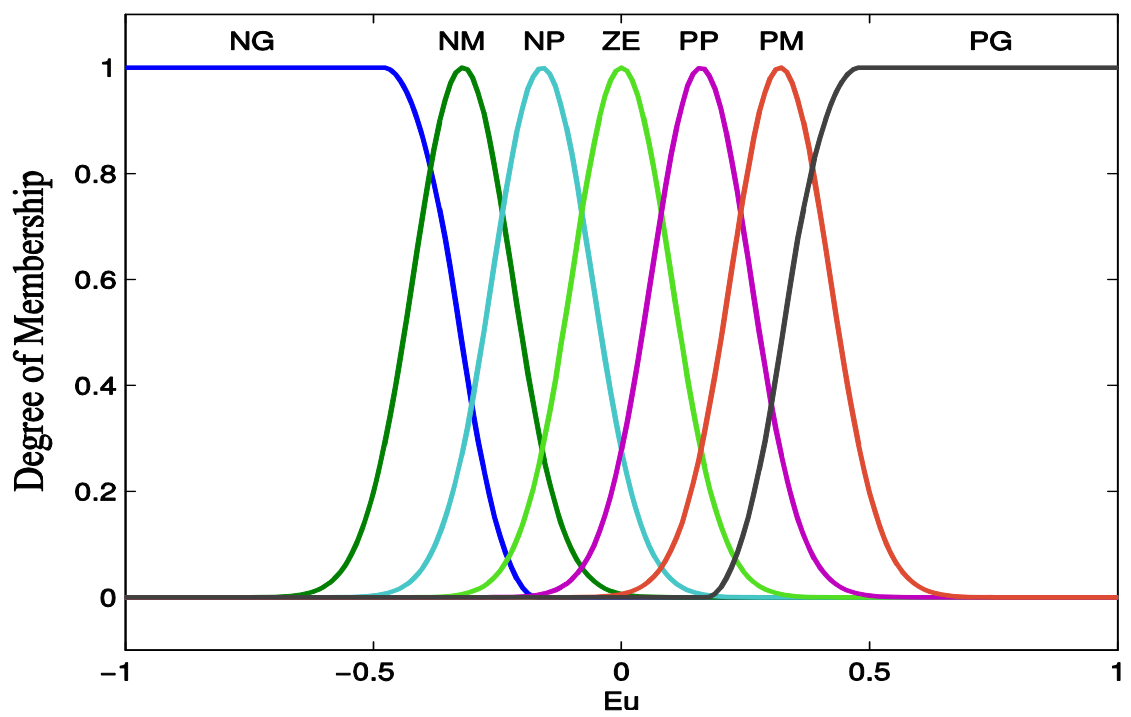

Fig. 5. Fuzzy sets for output voltage error

\section{RESUlTS AND DISCUSSION}

The control scheme and the operation of the converter in the microgrid were validated by simulation in Python 2.7 on a computer Intel(R) Core(TM) i7-7700HQ @ 2.80 GHz with Linux 64 bits kernel 4.13.0-46generic. We build the SEPIC converter model using system-level models of semiconductor switches (general behaviour, not specific devices). The parameters of the models used in the circuit were:

- MOS Field Effect Transistor (MOSFET, $\mathrm{Q}_{1}, \mathrm{Q}_{2}$ and $\mathrm{Q}_{3}$ ):
o Type: Equivalent line
o Forward voltage: $0.8 \mathrm{~V}$
o Bulk resistance: $1 \mathrm{~m} \Omega$
o Reverse resistance: $100 \mathrm{k} \Omega$

- $\mathrm{L}_{1}$ and $\mathrm{L}_{2}$ :
o Inductance: $47 \mathrm{uH}$
o Parasitic resistance in series: $1 \mathrm{~m} \Omega$

- $\mathrm{L}_{3}$ :

o Inductance: $220 \mathrm{nH}$

o Parasitic resistance in series: $1 \mathrm{~m} \Omega$

- $\mathrm{C}_{1}$ :

o Capacitance: $440 \mathrm{uF}$

o Parasitic resistance in series: $1 \mathrm{~m} \Omega$ 
- $\mathrm{C}_{2}$ :

o Capacitance: $220 \mathrm{uF}$

o Parasitic resistance in series: $1 \mathrm{~m} \Omega$

The battery is rated to supply or absorb a power of $100 \mathrm{~W}$ at any source/load condition. The model used for the battery allows the input/output current to be considered as load/unload current, and to increase/reduce its nominal voltage according to the power flow.

The architecture assumed in the simulation includes at least one power source connected to the system's DC bus. In this way there is always power from the DC bus to the battery. The behaviour of this current is assumed constant in the model, but can be variable without affecting the system or the control unit. This behaviour is controlled with the $d_{3}$ duty cycle. Due to this constant behaviour, a constant charge of the battery is observed in the simulations.

The simulations include a response time of the control unit of 100 us. This time is what a digital device would require to digitize the voltage and current signals, calculate the system state variables, look up the values in a table stored in ROM with the results of off-line simulation of the hybrid fuzzy-sliding control block, and apply the corresponding duty cycle to each of the converter's switches.

The control structure could not be implemented online on an embedded device due to the time required for its calculations. For the implementation it is proposed to simulate the hybrid fuzzy-sliding control scheme for all possible combinations of values of the state variables, and the results, to store them in a table in ROM memory inside the digital device. This allows control decisions to be made very quickly, in fact, this strategy was also used in the simulations presented here.

We perform two kinds of simulations: with constant load and with variable load. These simulations allow to determine the operation of the proposed control scheme, and to observe the capacity of the battery to absorb/deliver power while regulating the DC bus voltage, and therefore the stability of the microgrid. The constant load simulation was performed with an output power of $38.4 \mathrm{~W}$ (a constant output current of $0.8 \mathrm{~A}$, Fig. $6)$.
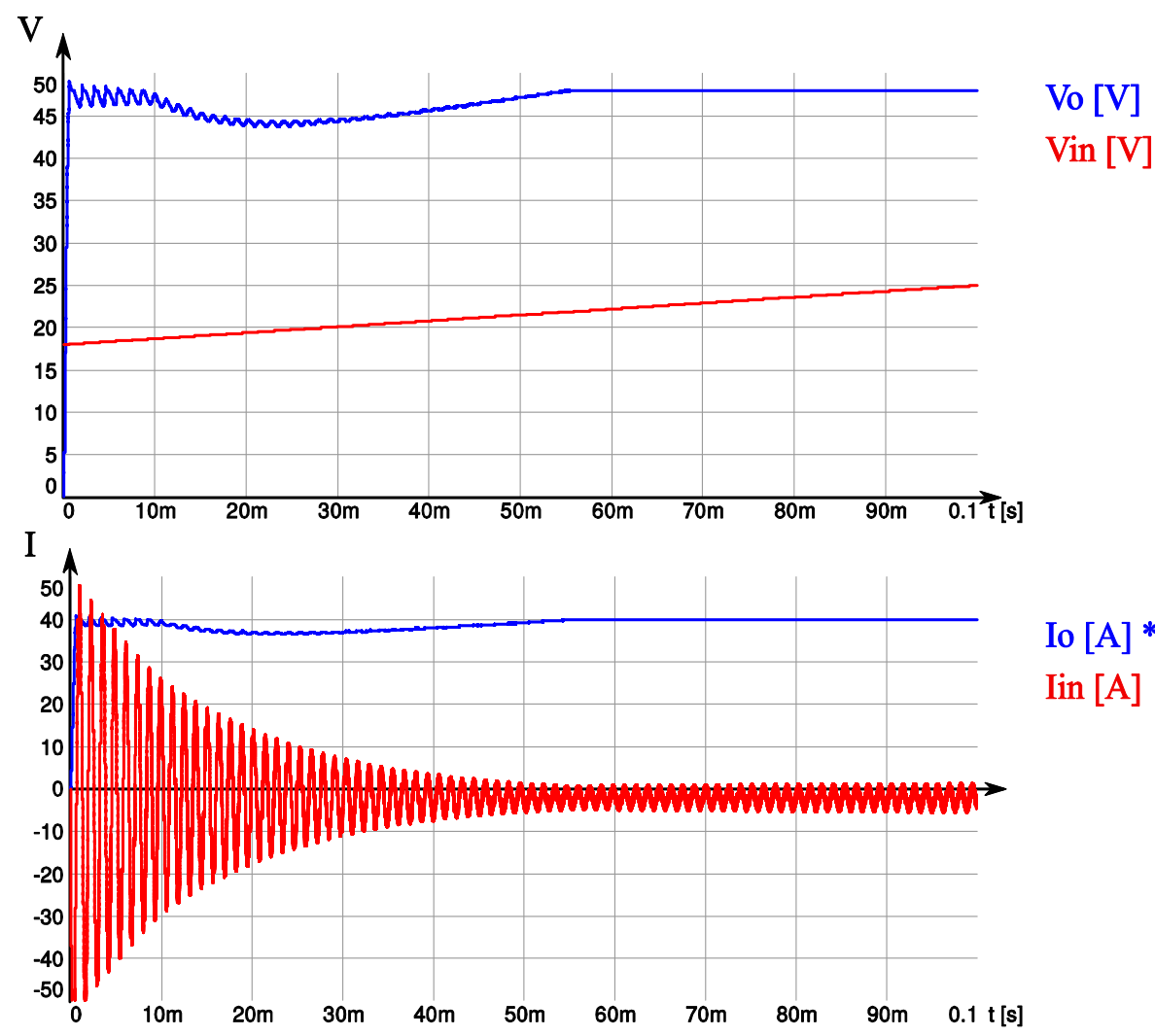

Io $[\mathrm{A}] * 50$

Iin $[\mathrm{A}]$

Fig. 6. Input (red) and output (blue) voltages and currents of the converter for constant load 
In operation with constant load it is possible to observe the transient connection of the converter. We assume that there is a certain amount of power in the battery (initial $18 \mathrm{~V}$ battery voltage), and that it absorbs power while feeding the 0.8 A charge. The capacitors and DC chokes of the converter have no stored energy, so when the converter is connected a large amount of current is consumed to charge them. In addition, the voltage on the $\mathrm{DC}$ bus of the microgrid is not regulated (assumed to be $0 \mathrm{~V}$ initially) so the inverter must quickly stabilize the microgrid.

After an initial transient of about $55 \mathrm{~ms}$, the power flow in the converter has reached a steady state. However, during the entire transient period the converter regulates the DC bus voltage using both the power of the battery and the power sources connected to the microgrid. Current flows tend to be high while the converter and DC bus are stabilized.Fig. 7 shows what happens when the load requirement for the converter doubles after it has reached its steady state (at $70 \mathrm{~ms}$ ).

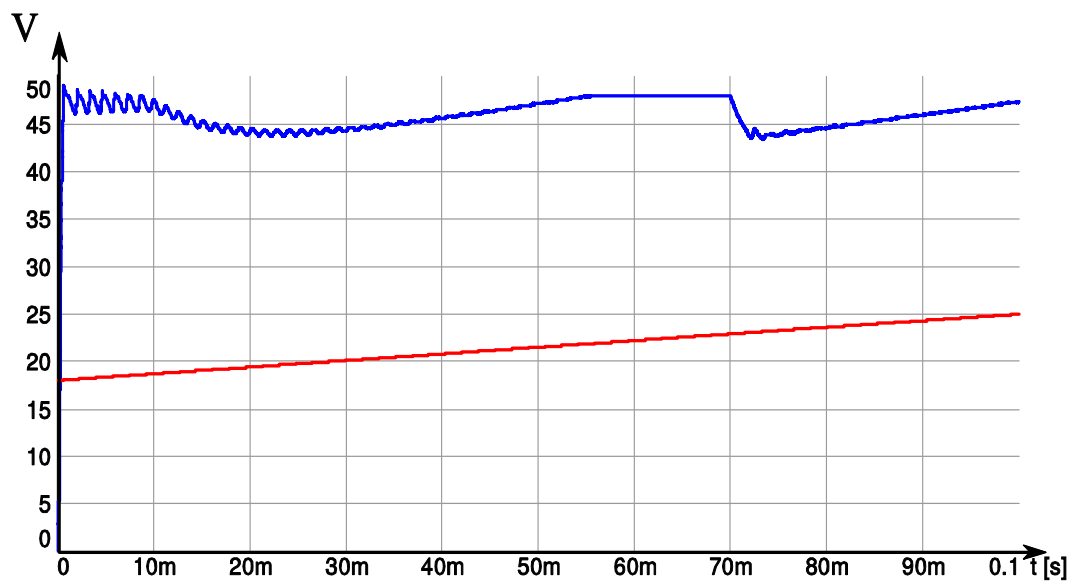

$$
\begin{aligned}
& \text { Vo [V] } \\
& \text { Vin [V] }
\end{aligned}
$$

I



Fig. 7. Input (red) and output (blue) voltages and currents of the converter for variable load

When the load unexpectedly increases, a new transient occurs in the converter. However, this new transient is much smaller than the initial one, the current does not present large current peaks (in fact, a small $6.7 \%$ transient is observed in the output current with a duration of only $2 \mathrm{~ms}$, we don't see peaks in the input current). The output voltage transient reaches a drop of $10.4 \%$ and lasts less than $30 \mathrm{~ms}$.After this $30 \mathrm{~ms}$ the converter reaches its new stationary state point.

An additional restriction of the control unit is to limit the maximum current delivered to the battery. The limit was set at 50 A for maximum $1 \mathrm{~ms}$. The voltage regulation falls mainly on the ratio of $d_{1}$ to $d_{2}$, but the control of the battery charge current depends mainly on $d_{3}$. This power limit controls the duration of the converter's initial transient.

\section{CONCLUSION}

In this paper we propose a control strategy for a bi-directional SEPIC converter that guarantees the regulation and stability of the voltage in a DC microgrid, and that also presents an excellent response to transients due to changes in the charge or storage batteries. The scheme proposes the use of a single control unit on an embedded digital system. The proposed control defines two control surfaces: one near to the converter's stability point and the other for transients, where power regulation is required. Near to the equilibrium point the main purpose is to regulate the output voltage (DC bus voltage), while during transients the amount of current in the converter is mainly controlled. By simulating the theoretical model of the system, the performance of the control strategy 
was observed in the event of changes in the charge and in the battery. The proposed control scheme successfully kept the DC bus voltage constant, and limited the behavior of the current transients.

\section{ACKNOWLEDGMENT}

This work was supported by the Universidad Distrital Francisco José de Caldas, in part through CIDC, and partly by the FacultadTecnológica. The views expressed in this paper are not necessarily endorsed by Universidad Distrital. The authors thank the research groups ARMOS and DIGITI for the evaluation carried out on prototypes of ideas and strategies.

\section{REFERENCES}

[1] E. Franco, R. Plazas, A. Gil, R. Franco and E. Gomez, Pilot nanogrid at Universidad del Valle for research and training in control and management of electrical networks in non-interconnected areas, IEEE 3rd Colombian Conference on Automatic Control (CCAC 2017), 2017, pp. 1-6.

[2] S. Elangovan, Recent trends in sustainable development of renewable energy, International Conference on Advances in Electrical Technology for Green Energy (ICAETGT 2017), 2017, pp. 148-150.

[3] M. Faisal, M. Hannan, P. Jern, A. Hussain, M. Bin and F. Blaabje, Review of energy storage system technologies in microgrid applications: Issues and challenges, IEEE Access, vol. 6, 2018: pp. 35143-35164.

[4] X. Yinliang and S. Xinwei, Optimal control based energy management of multiple energy storage systems in a microgrid, IEEE Access, vol. 6, 2018: pp. 32925-32934.

[5] U. Damisa, N. Ikechi and Y. Sun, Microgrid energy and reserve management incorporating prosumer behind-the-meter resources, IET Renewable Power Generation, vol. 12(8), 2018: pp. 910-919.

[6] M. Cook, G. Parker, R. Robinett and W. Weaver, Decentralized mode-adaptive guidance and control for dc microgrid, IEEE Transactions on Power Delivery, vol. 32(1), 2017: pp. 263-271.

[7] S. Anand and B. Fernandes, Optimal voltage level for DC microgrids, 36th Annual Conference on IEEE Industrial Electronics Society (IECON 2010), 2010, pp. 3034-3039.

[8] J. Galvis and J. Madrid, Sistema de control difuso para motor de corriente continua sin escobillas (bldc) sobre hardware embebido, Tekhnê, vol. 13(2), 2016: pp. 43-48, ISSN 1692-8407.

[9] S. Augustine, N. Lakshminarasamma and M. Kumar, Control of photovoltaic-based low-voltage dc microgrid system for power sharing with modified droop algorithm, IET Power Electronics, vol. 9(6), 2016: pp. 1132-1143.

[10] W. Haojie, H. Minxiao, J. Guerrero, J. Vasquez and B. Teshager, Distributed secondary and tertiary controls for I-V droop-controlledparalleled DC-DC converters, IET Generation, Transmission \& Distribution, vol. 12(7), 2018: pp. 1538-1546.

[11] S. Kumar, M. Mishra, A. Ukil and H. Gooi, Dc grid voltage regulation using new hess control strategy, IEEE Transactions on Sustainable Energy, vol. 8(2), 2017: pp. 772-781.

[12] S. Majeed, A. Xin, S. Yingyun, Z. Chen and S. Zhou, Voltage and frequency control strategies of hybrid ac/dc microgrid: a review, IET Generation, Transmission \& Distribution, vol. 11(2), 2017: pp. 303-313.

[13] C. Xia, S. Mengxuan, S. Haishun, L. Yan and H. Haibo, Distributed cooperative control and stability analysis of multiple dc electric springs in a de microgrid, IEEE Transactions on Industrial Electronics, vol. 65(7), 2018: pp. 5611-5622.

[14] S. Durgadevi and M. Gopinath, Analysis and design of single phase power factor correction with DC-DC SEPIC converter for fast dynamic response using genetic algorithm optimised pi controller, IET Circuits, Devices \& Systems, vol. 12(2), 2018: pp. 164-174.

[15] L. Sin-Woo and D. Hyun-Lark, Isolated SEPIC DC-DC converter with ripple-free input current and lossless snubber, IEEE Transactions on Industrial Electronics, vol. 65(2), 2018: pp. 1254-1262.

\section{AUTHOR PROFILE}

Fredy Hernán Martínez Sarmiento. PhD in Engineering - Systems and Computation, Professor at the Universidad Distrital Francisco José de Caldas, Director and principal researcher of the ARMOS research group.

Fernando Martínez Santa. MSc in Electronic and Computer Engineering, Professor at the Universidad Distrital Francisco José de Caldas, Researcher of the ARMOS research group.

Edwar Jacinto Gómez. MSc in Sciences of the Information and Communications, Professor at the Universidad Distrital Francisco José de Caldas, Researcher of the ARMOS research group. 